San Jose State University

SJSU ScholarWorks

Master's Theses

Master's Theses and Graduate Research

Summer 2015

\title{
The relationship between employee engagement and survey response rate with union membership as a moderator
}

Alexandra Mariah de la Rocha

San Jose State University

Follow this and additional works at: https://scholarworks.sjsu.edu/etd_theses

\section{Recommended Citation}

de la Rocha, Alexandra Mariah, "The relationship between employee engagement and survey response rate with union membership as a moderator" (2015). Master's Theses. 4582.

DOI: https://doi.org/10.31979/etd.z4c6-uv9d

https://scholarworks.sjsu.edu/etd_theses/4582

This Thesis is brought to you for free and open access by the Master's Theses and Graduate Research at SJSU ScholarWorks. It has been accepted for inclusion in Master's Theses by an authorized administrator of SJSU ScholarWorks. For more information, please contact scholarworks@sjsu.edu. 


\title{
THE RELATIONSHIP BETWEEN EMPLOYEE ENGAGEMENT AND SURVEY RESPONSE RATE WITH UNION MEMBERSHIP AS A MODERATOR
}

\author{
A Thesis \\ Presented to \\ The Faculty of the Department of Psychology \\ San José State University \\ In Partial Fulfillment \\ of the Requirements for the Degree \\ Master of Science
}

by

Alexandra M. de la Rocha

August 2015 
(C) 2015

Alexandra M. de la Rocha

ALL RIGHTS RESERVED 
The Designated Thesis Committee Approves the Thesis Titled

\section{THE RELATIONSHIP BETWEEN EMPLOYEE ENGAGEMENT AND SURVEY} RESPONSE RATE WITH UNION MEMBERSHIP AS A MODERATOR

$$
\text { by }
$$

Alexandra M. de la Rocha

\section{APPROVED FOR THE DEPARTMENT OF PSYCHOLOGY SAN JOSÉ STATE UNIVERSITY}

August 2015
Dr. Howard Tokunaga
Department of Psychology
Dr. Megumi Hosoda
Department of Psychology
Dr. Chris Lawson
Pacific Gas and Electric Company 


\section{ABSTRACT \\ THE RELATIONSHIP BETWEEN EMPLOYEE ENGAGEMENT AND SURVEY RESPOSNE RATE WITH UNION MEMBERSHIP AS A MODERATOR}

by Alexandra M. de la Rocha

Research has examined the benefits of having an engaged workforce. One way of measuring employee engagement is through organizational surveys. Survey response rate represents voluntary participation behavior and may be an outcome of employee engagement. However, research has not examined survey participation behavior as an outcome of employee engagement or factors that might influence this relationship. Thus, the purpose of the present study was to examine the relationship between dimensions of employee engagement (vigor, dedication, and absorption) and survey response rate at the aggregate level and to examine how this relationship varied as a function of percentage of union membership. Analyses were conducted for small and large groups because they had different work environments. The researcher found that there was a significant positive relationship between aggregate employee engagement levels and survey response rate. Moreover, this relationship was stronger for large groups than small groups, suggesting that group size influences the relationship between aggregate employee engagement and survey response rate. Regarding the moderating effect, union membership influenced the relationship between dedication and survey response rate only in small groups. These findings suggest that in small groups, the percentage of union membership in a group influenced the relationship between a strong sense of pride and personal accomplishment and survey response rate. 


\section{ACKNOWLEDGEMENTS}

I would like to thank my thesis committee for their support and countless hours of assistance. Howard, thank you for being my thesis chair and providing me with guidance through the entire process of writing my thesis. I appreciate the many discussions we had on-campus and late night phone calls to ensure that progress was made. You were influential in helping me process the uniqueness of my data and I appreciate your insights and feedback. Megumi, thank you for working with the fast paced deadline I was aiming for. I value your detailed feedback, thoughtful questions, and grammatical corrections. Chris, thank you for your guidance and support. I can clearly remember the day that you came to me and asked what topic I was thinking about for my thesis. Without that probing that question, my curiosity about employee engagement would not have blossomed into this thesis.

To my family and friends, thank you for your love, support, and understanding of my inability to be social these last few months. Mom and Dad, thank you for always supporting me in all of my endeavors. At a very young age, you instilled in me a strong love for learning that propelled me to strive for my Master's Degree. I am very grateful for all of the sacrifices you have made for me and want to say that none of this would have been possible without you both.

Nathan, thank you for all of your love and support. Without you, I am not sure how I would have kept my sanity during the process of writing my thesis. Thank you for "tearing apart" my introduction, listening to my endless rants, and for reminding me to relax and have fun. 


\section{TABLE OF CONTENTS}

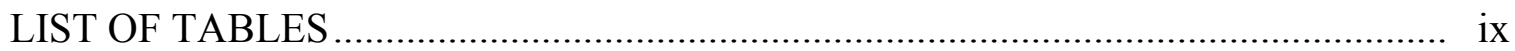





Employee Engagement …………………………..................................... 2

Outcomes of Employee Engagement........................................................... 4

Customer loyalty and satisfaction.........................................................

Productivity ................................................................................... 4

Organizational citizenship behaviors (OCBs) ……………………....... 5

Positive employee attitudes................................................................. 6

Retention, absenteeism, and shrinkage …………………………........ 6



Survey Response Rate................................................................................. 7

Organizational surveys....................................................................

Definition of survey participation and response rate ……...................... 9

Predictors of Participation and Survey Response Rate...................................... 10





Psychological predictors .................................................................... 12

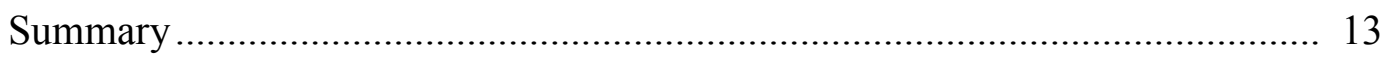

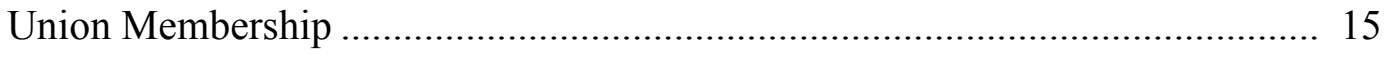

Research With Union Variables as Predictors ..................................................... 15 
Research With Union Variables as Moderators................................................ 17

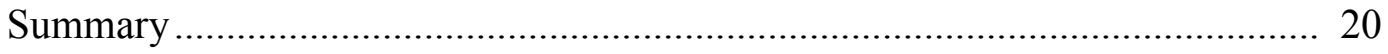

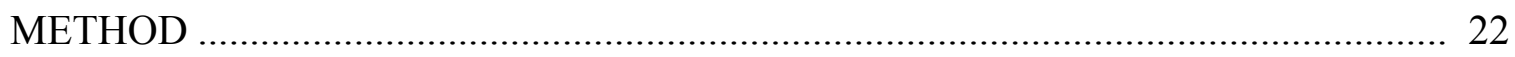

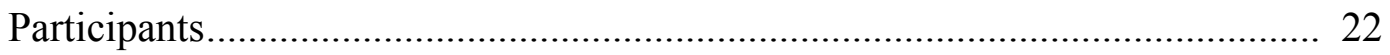

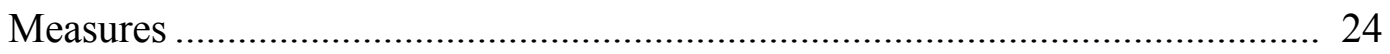

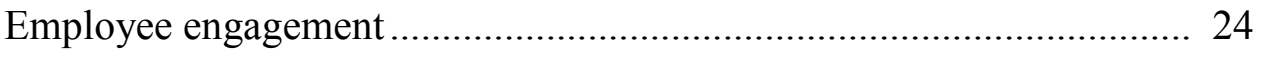

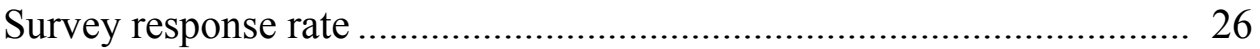

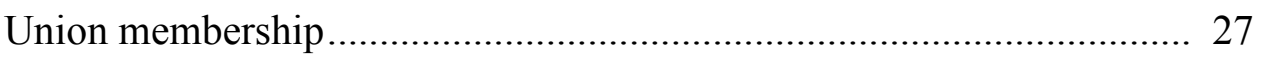

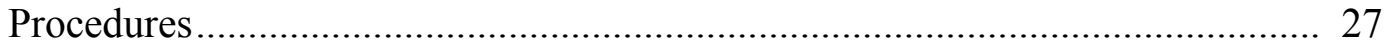

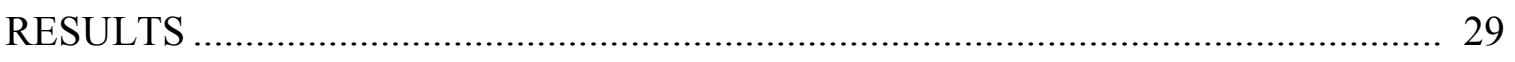

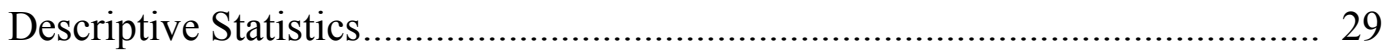



Large groups descriptive statistics ..................................................... 30

Group comparisons ………………………………………………... 30

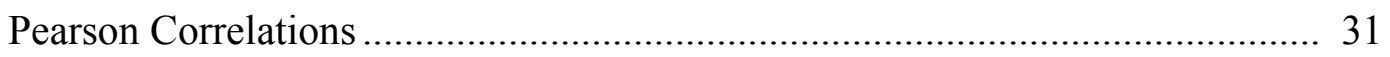

Small groups correlations …………………………………………..... 31

Large groups correlations ……………………………………….... 33



Standard Multiple Regression Analyses ......................................................... 35



Large groups analysis ......................................................................... 36




Hierarchical Multiple Regression Analyses....................................................... 38

Small groups analyses ..................................................................... 38

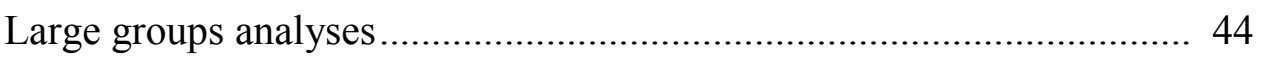



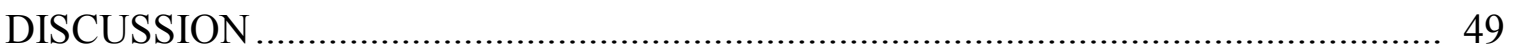



Relationships between variables .......................................................... 50

The relationship between employee engagement and survey

response rate

The moderating effect of union membership on the relationship

between employee engagement and survey response rate...................... 52

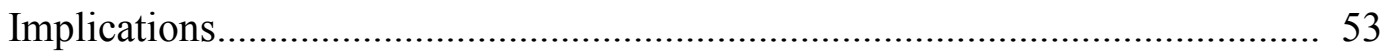

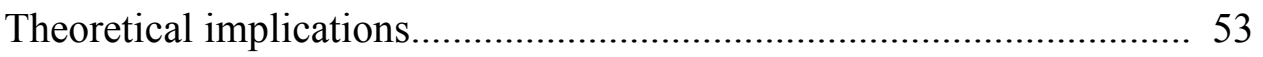

Practical implications ........................................................................... 54

Contributions of the Current Study ................................................................ 55

Limitations and Future Research .................................................................... 55



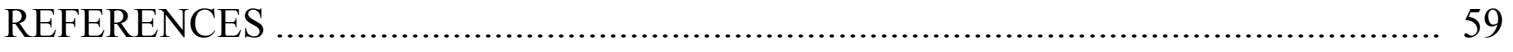

APPENDIX 


\section{LIST OF TABLES}

Table 1. Demographic Characteristics of Participants...................................................... 23

Table 2. Number of Survey Items in Each Dimension ............................................... 25

Table 3. Cronbach's Alphas for Each Year ................................................................... 26

Table 4. Descriptive Statistics for Groups Less than or Equal to 250 ........................... 30



Table 6. Intercorrelations Matrix for Groups Less than or Equal to 250....................... 33

Table 7. Intercorrelations Matrix for Groups Greater than 250 ………........................ 34

Table 8. Standard Multiple Regression Analysis: Prediction of Survey Response Rate by Vigor, Dedication, and Absorption for Groups Less than or

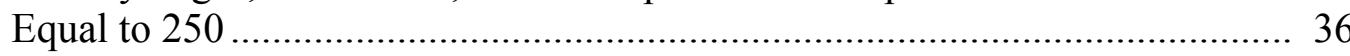

Table 9. Standard Multiple Regression Analysis: Prediction of Survey Response Rate by Vigor, Dedication, and Absorption for Groups Greater than 250 ....... 37

Table 10. Hierarchical Multiple Regression Analysis: Prediction of Survey Response Rate by Vigor and Union Membership for Groups Less than or Equal to 250 .

Table 11. Hierarchical Multiple Regression Analysis: Prediction of Survey Response Rate by Dedication and Union Membership for Groups Less than or Equal to 250

Table 12. Hierarchical Multiple Regression Analysis: Prediction of Survey Response Rate by Absorption and Union Membership for Groups Less than or Equal to 250

Table 13. Hierarchical Multiple Regression Analysis: Prediction of Survey Response Rate by Vigor and Union Membership for Groups Greater than 250

Table 14. Hierarchical Multiple Regression Analysis: Prediction of Survey Response Rate by Dedication and Union Membership for Groups Greater than 250

Table 15. Hierarchical Multiple Regression Analysis: Prediction of Survey 
Response Rate by Absorption and Union Membership for Groups Greater than 250 . 


\section{LIST OF FIGURES}

Figure 1. Interaction effects of dedication on survey response rate for groups

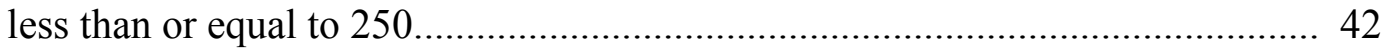




\section{Introduction}

In recent research and organizational surveys, employee engagement has emerged as an important construct of interest. According to Modern Survey (2013), approximately $13 \%$ of today's workforce is fully engaged, whereas $27 \%$ of employees are disengaged at work. The remaining $60 \%$ of employees are under and moderately engaged. This means that the majority of today's workforce is not engaged. Employee engagement has been found to be predictive of organizational outcomes, such as productivity, safety, retention, and customer satisfaction (i.e., Cowart, Crowell, \& Kaye, 2013; Gallup, 2012). According to Gallup (2002), actively disengaged employees pose a threat to companies because these employees act consistently against everything at work. Most importantly, actively disengaged employees engage in behaviors that erode the beneficial actions and attitudes of engaged employees (Maslach, Schaufeli, \& Leiter, 2001). Engaged employees exhibit more energy, experience a state of deep concentration with their work, and engage in extra-role behaviors. Thus, one possible outcome of employee engagement is survey response rate because it represents an aggregate of voluntary employee behaviors. Survey response rate is defined as the number of completed surveys divided by the number of eligible responding units in a sample (Skalland, 2011; Wiseman, \& Billington, 1984). Survey response rate is important because it ensures the representativeness of a sample in a population and the validity of survey results (i.e., Gobo, 2004; Hinkin \& Holtom, 2009; Tomaskovic-Devey et al., 1994). However, the relationship between employee engagement and survey response rate has not been examined. Furthermore, factors that may influence the relationship 
between employee engagement and survey response rate have not been examined. The relationship between psychological predictors and behavioral outcomes may be moderated by union variables (Bulger, 2001). In industries with unionized workers, engagement levels, survey response rates, and the influence of union membership are topics of particular interest. Therefore, the main goal of the present study was to examine the relationship between employee engagement and survey response rate and to examine how that relationship varies as a function of union membership.

\section{Employee Engagement}

Kahn was one of the first researchers to examine the construct of engagement. According to Kahn (1990), personal engagement is defined as "the harnessing of organizational members' selves to their work roles" (p. 694). Kahn's engagement is comprised of the simultaneous investment of an individual's physical, cognitive, and emotional energy in active job performance. Within Kahn's theory, engaged employees display behaviors that portray some combination of their self and obligatory roles. The self-role refers to an individual's personal life (self-expression, creativity, and ideas), whereas the obligatory role refers to the role that an individual must fulfill at work. Engaged employees are physically involved in tasks, cognitively attentive, and emotionally aware of their thoughts, feelings, values, and beliefs.

Although Kahn presented a theoretical model, the term engagement was never distinctly operationalized in that exact dimensions of engagement were not identified or defined. However, the construct of employee engagement has been operationalized in other studies. In particular, Schaufeli, Salanova, González-Romá, and Bakker (2002) 
sought to operationalize the dimensions of employee engagement. Schaufeli et al. (2002) defined, employee engagement as "a positive, fulfilling, work-related state of mind that is characterized by vigor, dedication, and absorption" (p. 74).

The first dimension of employee engagement, vigor, is defined as having high levels of energy, willingness to exert effort, and having mental resilience and persistence in one's work (Schaufeli et al., 2002). A distinct characteristic of vigor is that engaged employees are willing to go above and beyond when completing their work. Moreover, engaged employees feel energized by their work, have better mental resilience when performing tasks, and view work difficulties as a challenge.

The second dimension of employee engagement, dedication, is defined as having strong involvement, enthusiasm, pride, and a sense of significance (Schaufeli et al., 2002). Dedicated employees experience a strong sense of involvement both cognitively and affectively. Moreover, their behaviors reflect strong involvement in work-related and other company-related activities, such as volunteering, company events, and guestspeaker seminars. Engaged employees may also affectively and cognitively feel a sense of pride in the work they do and in the company they work for. Additionally, engaged employees feel that the work that they do is important and significant.

Lastly, the dimension of absorption is defined as a state of deep concentration and a state of being deeply engrossed in one's work (Schaufeli et al., 2002). An engaged employee experiencing absorption has a persistent state of deep concentration in which time seems to pass quickly. During this state of absorption, it can become difficult to remove oneself from work. While completing work, an engaged employee experiences a 
clear state of mind with effortless concentration and a sense of complete control. Furthermore, an engaged employee feels enjoyment when completing work-related tasks. This study adopts the definition of employee engagement proposed by Schaufeli et al. (2002).

\section{Outcomes of Employee Engagement}

Research has examined the relationship between employee engagement and organizational outcomes. Employee engagement has been found to be positively related to organizational outcomes, including customer loyalty/satisfaction, productivity, safety, and retention (Harter, Schmidt, Killham, \& Asplund, 2012).

Customer loyalty and satisfaction. Researchers have found that customers had higher customer engagement levels when they were serviced in departments with employees with high levels of engagement (Bates, 2004). Talent Management examined employee engagement and had similar findings: when engagement levels rose approximately $30 \%$, client satisfaction rates rose approximately $16 \%$ for the enterprise (Cowart, Crowell, \& Kaye, 2013). Other researchers have also examined whether employee engagement could predict customer satisfaction. Gallup (2012) found that top quartile companies with engaged employees had $10 \%$ higher customer satisfaction scores than bottom-quartile companies.

Productivity. In looking at the effect of employee engagement on productivity at the organizational level, researchers found that top-quartile companies with highly engaged employees had $21 \%$ higher productivity than bottom-quartile companies (Gallup, 2012). The Gallup organization studied 89 companies and compared top 
quartile and bottom quartile engagement levels and found that companies in the top quartile had 2.6 times higher earnings per share than those in the bottom quartile (Ott, 2007). Additionally, companies with highly engaged employees have experienced higher returns for shareholders (Irvine, 2009).

In a case study, Gallup examined whether employee engagement could predict productivity (i.e., net sales and return on investment). Employee engagement significantly predicted productivity such that productivity increased as employee engagement increased. For the company in the study, net sales increased by $300 \%$, and the company had a $600 \%$ return on investment (Robison, 2006).

In addition to profitability at the organizational level, researchers have examined the effects of employee engagement on productivity at the individual level. Rich, LePine, and Crawford (2010) examined the relationship between job engagement and job performance. They also examined antecedents (i.e., value congruence, perceived organizational support, and self core-evaluations) of job engagement. The researchers found that job engagement significantly mediated the relationships between antecedents and task performance; employees who had higher value congruence perceived more organizational support and higher core self-evaluation had higher engagement scores, which, in turn, led to better performance.

Organizational citizenship behaviors (OCBs). Research discussed in the previous section examined productivity at the organizational level (e.g., earnings per share and net sales) and at the individual level (i.e., job performance). Continuing with predictors at the individual level, researchers have examined the relationship between 
employee engagement and OCBs. Rich et al. (2010) found that job engagement mediated the relationship between three antecedents (value congruence, perceived organizational support, and core self-evaluations) and organizational citizenship behaviors. Employees who reported high value congruence, perceived greater organizational support, and had high core self-evaluations had significantly higher engagement scores, which led them to perform more OCBs.

Positive employee attitudes. Employee engagement has also been found to be predictive of positive attitudes, such as pride and confidence in the future. In particular, Modern Survey (2013) conducted a survey on employee engagement, organizational capabilities, and organizational direction. Participants $(N=1,000)$ included a sample of U.S. employees who worked full-time, were 18 years or older, and worked for organizations with over 100 employees. Industries included in the study were financial services, heavy manufacturing, health care, government, light manufacturing, retail trade, education, and business services. The researchers found that engaged employees had a greater willingness to refer the company to others, had a higher sense of pride, and had a higher sense of future and were more inspired by their company than disengaged employees.

Retention, absenteeism, and shrinkage. Researchers have also examined the effect of engagement on employee retention, absenteeism, and shrinkage (Cowart, Crowell, \& Kaye, 2013; Gallup, 2012; Modern Survey, 2013). In its study, Talent Management found that as employee engagement rose approximately $30 \%$ and turnover rates dropped approximately $15 \%$ for the enterprise (Cowart et al., 2013). More 
specifically, researchers have examined differences between engaged and disengaged employees (Gallup 2012; Modern Survey, 2013). For example, Modern Survey (2012) found that engaged employees had greater intent to stay with the company than disengaged employees, with $47 \%$ of disengaged and $18 \%$ of under-engaged employees actively looking to leave the company. Gallup (2012) also found that engaged employees exhibited 37\% less absenteeism, 25-65\% less turnover, and 28\% less shrinkage.

\section{Summary}

Research has shown employee engagement to be a predictor of many organizational outcomes. In particular, employee engagement has been found to be positively related to customer satisfaction, positive attitudes about an organization (e.g., pride and optimism about the future), productivity, OCBs, safety, and retention. Employee engagement has also been found to be negatively related to absenteeism and shrinkage. Thus, it is important for organizations to assess employees' level of engagement in the workplace. One way of measuring or assessing employee engagement is through regularly scheduled organization-wide surveys. In the next section, I will discuss organizational surveys and the importance of survey response rate. I will also discuss predictors of survey response rate (i.e., administration method, demographic variables and psychological variables).

\section{Survey Response Rate}

Organizational surveys. Organizational surveys have become common practice in many organizations. Organizational surveys are important because surveys provide mutual benefits for both organizations and employees. By administering a survey, an 
organization receives feedback critical to identifying issues with the organization's functioning. By participating, employees are given the opportunity to influence change in the organization by providing honest feedback about the organization and their work environment (Saari \& Scherbaum, 2011). According to Sugheir, Coco, and Kaupins (2011), administration of organizational surveys is a common practice, typically done at least every two years. In their meta-analysis, they found that the majority $(58.1 \%)$ of organizational surveys were administered at least once a year.

Organizations conduct surveys to quantitatively measure specific aspects of an organization as it relates to employee experience and the workplace (Church \& Waclawski, 2007). Examples of organizational employee surveys include attitude, opinion, satisfaction, and engagement surveys (Church \& Waclawski, 2007; Wyse, 2012). Other organizational surveys also measure behaviors, performance, and processes (Church \& Waclawski, 2007).

Many changes have been made to organizational surveys, especially through the use of technology. Examples include the administration of organizational surveys online and the linkage of employee surveys to organizational data. In particular, Saari and Scherbaum (2011) identified three types of surveys used by organizations: identified surveys, temporarily-identified surveys, and non-identified surveys. Identified surveys collect and retain unique identifying information of individual employees and link this information to their survey results. Employees' unique identifiers to survey results remain intact for future use. Temporarily-identified surveys identify employees by their unique identifying information only at the time of administration or for a short period of 
time following survey administration. The key difference between these two types of surveys is that employee responses can be identified using identified surveys, whereas employee responses using the temporarily-identified surveys are anonymous. The historically common method of collecting surveys is through non-identified surveys in which no identifiers are linked to employee responses and demographic information is collected within the survey itself.

Definition of survey participation and response rate. Past research has examined the concepts of employee voice and participation in the organization (e.g., Budd, Gollan, \& Wilkinson, 2010). Employee voice refers to expression of dissatisfaction at the individual, organizational, management, and employee-employer relationship levels. Employee participation occurs through many channels, including direct interactions between managers, peers, employees, membership of formal institutions, and organizational surveys (Budd et al., 2010). In particular, research has examined employee voice and participation with regard to union-represented employees. Through the emergence of labor unions in United States in the late 19th century, employees have been given a channel to voice their opinions and the potential to shape company polices regarding compensation, benefits, and productivity (Budd et al., 2010).

Although organizational surveys are useful tools for measuring feedback from employees, the quality of the information gathered in organizational surveys depends on survey participation. Survey participation refers to an individual's decision to partake in a survey (Mertler, 2003). In aggregate, individual survey participation results in a survey response rate, which is defined as the number of completed surveys divided by the 
number of eligible responding units in a sample (Skalland, 2011; Wiseman, \& Billington, 1984).

In an organizational setting, researchers have found survey response rates to be as low as 53\% (Tomaskovic-Devey, Leiter, \& Thompson, 1994). Some major concerns related to low survey response rate are the representativeness of the sample used in the survey and non-response bias (Gobo, 2004; Hinkin \& Holtom, 2009; Tomaskovic-Devey et al., 1994). Sample representativeness refers to having a sample that mirrors, and has survey results generalizable to, the population of interest (Gobo, 2004). Non-response bias refers to systematic (i.e., non-random) error that occurs when survey participants purposely do not take a survey. Non-response bias is a concern because it leads to a nonrepresentative sample, which poses a threat to the validity of a survey (TomaskovicDevey et al., 1994).

\section{Predictors of Participation and Survey Response Rate}

Survey methodology. There are many factors that can influence survey participation and response rate. In particular, one factor that affects survey response rate is the survey administration method. In an organizational setting, surveys are commonly administered via mail, internal mail, in-person, email, phone, and web. Research has demonstrated survey response rates to be as high or higher when survey administered electronically compared to traditional mail surveys (Baruch, \& Holtom, 2008).

Manfreda, Berzelak, Vehovar, Bosnjak, and Haas (2008) conducted a metaanalysis to determine whether survey administration method (web-based survey or alternative survey modes) affected survey response rate. Alternative survey 
administration methods examined were mail, telephone, fax, email, and other. Researchers found that web-based surveys had $11 \%$ lower survey response rates than other modes of survey administration. These findings are contradictory to what Baruch and Holtom (2008) found. However, it is important to note that studies included in the meta-analysis by Manfreda et al. included empirical studies with surveys administered to the general population, organizations, education, and army, whereas Baruch and Holtom examined empirical studies with surveys only administered in organizations.

Methodological factors that affect survey response rate include survey length, repeated mailings, and delivery method of further contact. Heberlein and Baumgartner (1978) found that initial survey response rate, survey length, salience of a topic, special third contact, and number of follow-up contacts explained $90 \%$ of variance in final survey response rate. In particular, survey length, special third contact, and number of follow-up contacts significantly predicted survey response rate such that people were more likely to participate in surveys when the length of the survey was shorter, were contacted in a way that was special (e.g., special delivery, telephone call, personal contact), or received multiple follow-up contact.

At the individual level, research has examined how organizational administration of surveys affects employee perceptions and response behaviors. Saari and Scherbaum (2011) examined existing literature on the relationship between the practice of linking employee opinion surveys to HR data and employee perceptions of privacy/anonymity and survey response rate. A key aspect of linkage analysis is that opinion surveys retained identifying information about each survey respondent over time. A review of the 
existing literature suggested that linked surveys were related to higher concerns for privacy/anonymity and lower survey response rate (Mertler, 2003; Saari \& Scherbaum, 2011; Thompson \& Surface, 2007).

Demographic predictors. Other factors that can affect survey response rate occur at the individual participant level. According to Heberlein and Baumgartner (1978) population type is related to survey response rate. They found that students, army personnel, and employees were more likely to respond to surveys than the general population. Edmondson, Barnes, and Gupte (2008) also studied the relationship between individual characteristics and survey response rate. Researchers examined existing research to develop a theoretical model about the influence of race or ethnicity of survey participants on response behaviors (i.e., non-response or acquiescent behavior). In general, employees of color had lower survey participation than Caucasian employees. Researchers proposed that the influence of race or ethnicity depended upon whether or not employees of color shared a positive or negative perception of the organization with others of the same ethnicity. When employees did not share a positive organizational perception with others of the same race/ethnicity, they were more likely not to respond for fear of identification or retaliation. When employees did not share a negative organizational perception with others of the same race/ethnicity, they were more likely not to respond or to conform their responses based on group member responses. That is, when employees of color did not share the same organizational perception as others of the same ethnicity, they were less likely to respond to surveys. 
Psychological predictors. Psychological predictors are variables of a psychological nature that predict outcomes. Saliency of a survey topic is an example of a psychological predictor that can influence survey response or non-response. Saliency refers to an individual's interest in and knowledge of a topic (Heberlein \& Baumgartner, 1978). Heberlein and Baumgartner found that saliency explained $50.5 \%$ of the variance in final response rate. Participants were more likely to participate in surveys when they were interested and knowledgeable about the survey topic.

\section{Summary}

In summary, previous research examined the relationships between survey methodology and individual predictors with survey response rate. However, research has not examined the relationship between organizational surveys and survey response rate. Previous research also examined the relationship between employee engagement and a variety of organizational outcomes (Gallup, 2012; Modern Survey, 2013; Rich et al., 2010). However, research has not examined the relationship between employee engagement and survey response rate. Employee engagement involves employees going above and beyond their normal duties and displaying behaviors and attitudes that exhibit vigor, dedication, and absorption with their work. One way of measuring employee engagement is through organizational surveys. Therefore, by voluntarily participating in organizational surveys, employees provide feedback and voice concerns to the organization. However, this requires that employees feel and think that their opinions and feedback matter to the organization. Survey response rate should be considered a positive index because it symbolizes something good about the organization, such as 
organizational concern for employees and organizational responsiveness based on employee feedback. Survey response rate could be an indicator of whether or not employees feel their voice is heard (Budd, Gollan, \& Wilkinson, 2010) and can possibly be a consequence of engagement. Therefore, the purpose of the current study was to examine the relationship between employee engagement and survey response rate. Higher employee engagement levels indicate that employees are more connected at work, more willing to perform extra tasks, and therefore, individuals may be more willing to voluntarily participate in surveys (Schaufeli et al., 2002). Engagement levels cannot be known for individuals who do not participate in the survey; therefore, aggregate engagement scores and group survey response rates can be used as a metric of voluntary survey response behavior at the aggregate level. Because employee engagement is a positive predictor and survey response rate is considered a positive index, it is hypothesized that there will be a positive relationship between the two variables.

Hypothesis 1: There will be a positive relationship between aggregate employee engagement levels and survey response rates such that the more engaged groups are, the more likely they are to have higher survey response rates.

In this study, employee engagement is a psychological predictor and survey response rate is a behavioral outcome. Previous research suggests that the relationship between a psychological predictor and a behavioral outcome may be moderated by a union variable (Bulger, 2001). In the next section, union membership will be discussed 
as a possible moderator of the relationship between employee engagement and survey response rate.

\section{Union Membership}

By definition, unions are organized associations formed to represent and protect employee interests, including work conditions, wage insecurity, and benefits (Hogler, Hunt, \& Weiler, 2015). Traditional industries with high union membership include manufacturing, construction, transportation, utilities, and communications, with the majority of unionization occurring in the Northeast and Midwest (Western \& Rosenfeld, 2011).

In the U. S., labor unions first emerged in the late 19th century (Brochu, \& Morin, 2012; Budd, Gollan, \& Wilkinson, 2010). Since the 1970s, union membership has declined drastically due to economics, globalization, and job growth in non-traditional union industries (Budd et al., 2010; Western \& Rosenfeld, 2011). In the private sector, union membership has declined from $34 \%$ to $8 \%$ for men and $16 \%$ to $6 \%$ for women since 1973. One perceived consequence of this decline in union membership is an increase in wage inequality between unionized and non-unionized workers. According to Western and Rosenfeld, wage inequality has increased by over $40 \%$ in the private sector.

\section{Research With Union Variables as Predictors}

The majority of studies conducted regarding unions have used union variables as predictors for job satisfaction (Gordon, \& Denisi, 1995; Odewahn \& Petty, 1980). In particular, research has examined the relationship between union membership and job satisfaction. Much research has found that union employees had significantly lower 
levels of job satisfaction than non-union employees (Bryson, Cappellari \& Lucifora, 2004; Hammer \& Avgar, 2005; Heywood, Siebert, \& Wei, 2002; Odewahn \& Petty, 1980; Renaud, 2002; Schwochau, 1987). Bryson, Cappellari, and Lucifora (2010) argue that these differences occur as a result of non-random group differences. That is, individuals who are less satisfied self-select or sort into the union membership group (Heywood et al., 2002). However, other research has found that union membership did not affect job satisfaction (Gordon, \& Denisi, 1995). One likely reason for the discrepancy of these findings is that findings depended on how researchers controlled for working conditions across different samples (Gordon, \& Denisi, 1995; Renaud, 2002). According to Renaud (2002), union employees typically have worse working conditions than non-union employees, which could explain why unionized workers have lower job satisfaction than non-union workers. Once working conditions have been controlled for, research has found no differences on job satisfaction between union and non-union employees (Renaud, 2002).

Research has also studied the relationship between union variables and other attitudinal outcomes (Hammer \& Avgar, 2005; Odewahn \& Petty, 1980). For example, Odewahn and Petty (1980) examined the relationship between union membership and attitudinal outcomes (job satisfaction, stress, and personal competence) and found that union employees had significantly higher anxiety levels and lower levels of personal competence than non-union employees. Brochu and Morin (2012) studied the relationship between union membership and perceived job insecurity, finding that union 
employees were significantly more likely than non-union employees to feel insecure about current and future jobs.

Modern Survey (2013) examined the relationship between union membership and employee engagement. Modern Survey conducted a national longitudinal study of employee engagement from 2007 to 2011 . This study consisted of a representative sample of U. S. working adults ages 18 years or older from different regions in the U.S. Participants were selected to match demographics from U.S. census data. Of that sample, 141 participants were union members and 559 were non-union employees. Participants were sorted into four categories of engagement levels: fully engaged, moderately engaged, under engaged, and disengaged. Researchers found union members (33\%) were more likely than non-union members $(28 \%)$ to be disengaged. Also, non-union members were more likely than union employees to describe themselves as moderately engaged. Both union members $(37 \%, 11 \%)$ and non-union members $(36 \%, 12 \%)$ were almost equally likely to describe themselves as under-engaged or fully engaged, respectively.

\section{Research With Union Variables as Moderators}

A plethora of research has examined union variables as predictors for attitudinal outcomes. However, relatively little research has examined the extent of union variables as moderators. Research has examined the moderating effects of psychological union variables (perceived union tolerance and perceived union support) on the relationship between sexual harassment and psychological and behavioral outcomes. Mellor and Golay (2014) examined the moderating effect of two union-related variables (perceived union tolerance for sexual harassment and perceived union support) on the relationship 
between sexual harassment and mental health, with the goal of identifying conditions under which the toxicity of harassment is reduced. Perceived union tolerance for sexual harassment refers to a union member's belief regarding union tolerance for harassment based on union policy and policy-practice on sexual harassment. Perceived union support refers to a union member's beliefs about union responsiveness to that member. Participants included in this study were women who had union membership and lived in Connecticut, Massachusetts, and New York.

Mellor and Golay (2014) found two significant interaction effects for the relationship between sexual harassment and mental health. First, perceived union tolerance and perceived union support influenced the relationship between sexual harassment and mental health. Under conditions of high perceived union tolerance for sexual harassment and low perceived union support, women who experienced greater sexual harassment had higher negative mental health. Under conditions of low perceived union tolerance for sexual harassment and high perceived union support, there was no significant relationship between sexual harassment and negative mental health. Consequently, union involvement affected relationships such that union involvement produced a buffering effect on relationships. In other words, when employees did not feel supported by their unions (the union tolerated sexual harassment and did not support members), sexual harassment adversely affected their mental health. However, when employees felt supported by their unions (the union did not tolerate sexual harassment and supported members), the negative effect of harassment on mental health was nullified. 
Bulger (2001) examined two relationships: (a) the relationship between reported sexual harassment and psychological consequences (perceived distress), and (b) the relationship between organizational tolerance for sexual harassment and the reporting of harassment. The moderating effects of union resources and union tolerance for sexual harassment were also examined. Union resources refer to "the number of resources that a union has in place for dealing with sexual harassment" (p. 728). Union tolerance for sexual harassment refers to the degree to which a union is perceived as tolerant of sexual harassment. Participants included in this study were women who were union members and lived in the Northeast and Midwest United States.

Bulger (2001) first examined the relationship between reported sexual harassment and psychological outcomes. The researcher found that union tolerance moderated the relationship between reported sexual harassment and negative psychological outcomes; however, results did not support their hypothesis of a buffering effect. Instead, union tolerance influenced the relationship between organizational tolerance for sexual harassment and negative psychological outcomes, such that women in organizations with perceived low union tolerance for sexual harassment experienced more negative psychological outcomes when they reported high sexual harassment. When women in unions perceived high union tolerance for sexual harassment, there was no significant relationship between reporting of sexual harassment and negative psychological outcomes. These results suggest that unions with low tolerance for sexual harassment exacerbated the effect of sexual harassment on negative psychological outcomes. The second relationship that Bulger examined was the relationship between organizational 
tolerance for sexual harassment and reported sexual harassment. The researcher found that union resources moderated the relationship between organizational tolerance for sexual harassment and reported sexual harassment. When women were in unions with fewer resources, the relationship between organizational tolerance for sexual harassment and reported sexual harassment was strong, such that women were more likely to report experiencing sexual harassment when organizational tolerance for harassment was high. However, the relationship was weaker when women were in unions with more resources for dealing with sexual harassment such that women were less likely to report experiencing sexual harassment even when organizational tolerance for harassment was high. These findings suggest that unions that have the resources needed to support members can neutralize the negative effects of organizations on employees.

\section{Summary}

Research in the previous sections examined union variables as moderators of the relationship between a psychological predictor and psychological and behavioral outcomes (Bulger, 2001; Mellor \& Golay, 2014). Research supports a union variable as a moderator between a psychological predictor and a behavioral outcome (Bulger, 2001). In relation to the current study, the findings of Bulger, and Mellor and Golay suggest that union involvement moderates relationships such that the relationship between a psychological predictor and a behavioral outcome is weakened when union involvement is high. This implies that greater union involvement weakens the relationship between negative events and negative outcomes. Furthermore, it suggests that unions are protecting employees (buffering the effect of a negative work environment). From this, it 
can also be inferred that union involvement should strengthen the relationship between positive predictors and positive outcomes. Conversely, the lack of union involvement should weaken the relationship between positive predictors and positive outcomes. Therefore, the second purpose of the current study is to examine if union membership moderates the relationship between a psychological predictor (employee engagement) and behavioral outcome (survey response rate).

Hypothesis 2: Union membership will moderate the relationship between aggregate employee engagement levels and survey response rate, such that union membership will produce a stronger positive relationship between employee engagement and survey response rate than non-union membership. In other words, when union members are highly engaged, they will be more likely than non-union members to participate in the survey. When union members are not engaged, they will be less likely than non-union members to participate in the survey. 


\section{Method}

\section{Participants}

At the individual level, the target population was employees at a utility company, 18 years or older. Data were collected at the organization using company-wide employee engagement surveys administered in 2008, 2009, 2010, and 2011. All employees who worked part-time or full-time and had been with the company for a minimum of six months were invited to take the engagement survey. Contracted workers were not invited to participate in the survey because they were employed by an outside temporary staffing agency and not by the company.

To protect the confidentiality of participants, demographic data were suppressed for participants in departments with fewer than 10 participants. Data were also suppressed for individuals when fewer than 10 participants in a department shared the same demographic information. Because union membership was considered to be a demographic variable, union membership information was suppressed within departments that met the criteria stated above. Consequently, 32,186 (54.81\%) of the 58,728 participants were excluded, resulting in a sample size of 26,542 .

Participants consisted of $80.8 \%$ males and $19.2 \%$ females. Approximately $38 \%$ of the respondents were in the age range of 45 to 54; the least frequent age ranges were less than $25(1.7 \%)$ and more than $65(.1 \%)$. The majority of participants were White (75.2\%), followed by Hispanic/Latino (14.8\%), Asian (6.8\%), African American (3.2\%), and American Indian/Alaskan Native (.1\%). Also, 83.7\% of participants were union members, and $16.7 \%$ were non-union members. 
Table 1

Demographic Characteristics of Participants $(N=26,542)$

\begin{tabular}{|c|c|c|}
\hline Variables & Frequency & Percentage \\
\hline \multicolumn{3}{|l|}{$\overline{\text { Survey Administration Year }}$} \\
\hline 2008 & 6,187 & 23.0 \\
\hline 2009 & 5,441 & 20.5 \\
\hline 2010 & 6,068 & 22.9 \\
\hline 2011 & 8,846 & 33.3 \\
\hline \multicolumn{3}{|l|}{ Survey Method } \\
\hline Web & 12,367 & 46.6 \\
\hline Paper & 14,175 & 53.4 \\
\hline \multicolumn{3}{|l|}{ Age Range } \\
\hline Less than 25 & 448 & 1.7 \\
\hline $25-34$ & 5,513 & 20.8 \\
\hline $35-44$ & 4,930 & 18.6 \\
\hline $45-54$ & 9,937 & 37.4 \\
\hline $55-64$ & 5,680 & 21.4 \\
\hline More than 65 & 34 & .1 \\
\hline \multicolumn{3}{|l|}{ Gender } \\
\hline Male & 21,451 & 80.8 \\
\hline Female & 5,091 & 19.2 \\
\hline \multicolumn{3}{|l|}{ Ethnicity } \\
\hline \multicolumn{3}{|l|}{ American Indian/Alaskan } \\
\hline Native & 28 & .1 \\
\hline Asian & 1,797 & 6.8 \\
\hline Black/African American & 838 & 3.2 \\
\hline Hispanic/Latino & 3,919 & 14.8 \\
\hline White & 19,960 & 75.2 \\
\hline \multicolumn{3}{|l|}{ Union Membership } \\
\hline Union Member & 22,215 & 83.7 \\
\hline Non-Union member & 4,327 & 16.3 \\
\hline
\end{tabular}

In aggregate, the target population was departments (groups) at the organization. Criteria for inclusion were: (a) having 10 or more employees who participated in the survey, and (b) had union membership or non-membership identified. Departments that met these criteria were treated as one responding unit. In total, there were 180 
responding units with number of participating employees ranging from 31 to 2,683 ( $M=$ 261.39, $S D=298.55)$. Because the survey was administered multiple years, some departments were represented in the sample more than once. In total, there were 78 unique departments, with 33 departments being represented twice and 12 departments represented three times. In the present study, statistical analyses were conducted at the aggregate level with 180 departments (groups).

\section{Measures}

Employee engagement. At the individual level, employee engagement was captured using the Employee Engagement Index, which consisted of 14 survey questions (see Appendix). Survey questions were benchmarked against top performing companies in the U.S. (Fortune 200) and were validated at the organization via pilot studies during survey development in 2008. The Employee Engagement Index was used at the organization from 2008 to 2011 . The response format for the survey questions consisted of a 5-point Likert scale measuring how strongly individuals agreed or disagreed with statements ( 1 - Strongly Agree to 5 - Strongly Disagree). For analysis, scores were reverse coded so that a high score indicated greater engagement. In aggregate, mean engagement scores were calculated for each group (department) to determine the average engagement score for that responding unit. It is important to note that the number of items varied each year (see Table 2). To determine the internal consistency reliability of the dimensions, a reliability test was conducted on each dimension for each year (see Table 3). 
Table 2

\begin{tabular}{cccc}
\multicolumn{4}{c}{ Number of Survey Items in Each Dimension } \\
\hline Year & Vigor & Dedication & Absorption \\
\cline { 2 - 4 } 2008 & 5 & 6 & 3 \\
2009 & 5 & 6 & 3 \\
2010 & 5 & 6 & 3 \\
2011 & 5 & 4 & 1 \\
\hline
\end{tabular}

This study adopted the definition of employee engagement proposed by Schaufeli, Salanova, González-Romá, and Bakker (2002). Employee engagement is defined as “a positive, fulfilling, work-related state of mind that is characterized by vigor, dedication, and absorption" (Schaufeli et al., 2002, p. 74).

The first dimension of employee engagement, vigor, is defined as having high levels of energy, willingness to exert effort, and having mental resilience and persistence in one's work. Vigor was measured using five survey items. An example question theme in this dimension was "invigorate." Across all four years, Cronbach's alphas indicated that this scale was highly reliable with alphas ranging from .83 to .84 .

The second dimension of employee engagement, dedication, is defined as having strong involvement, enthusiasm, pride, and a sense of significance. Dedication was measured using six survey items for years 2008, 2009, and 2010, and three items in 2011. An example question theme in this dimension was "belonging." Across all four years, Cronbach's alphas indicated that this scale was highly reliable with alphas ranging from .84 to .85 .

The third dimension of employee engagement, absorption, is defined as a state of deep concentration and a state of being deeply engrossed in one's work (Schaufeli et al., 
2002). Absorption was measured using three survey items for years 2008, 2009, and 2010. However in 2011, only one survey item was used. The one question theme that was used in all years was the "ability to focus." Across 2008 to 2011, Cronbach's alphas indicated that this scale was highly reliable with alphas ranging from .81 to .82 .

Table 3

Cronbach's Alphas for Each Year

\begin{tabular}{|c|c|c|c|c|}
\hline Year & $\underline{\mathrm{N}}$ & Vigor & Dedication & Absorption \\
\hline 2008 & 6,187 & .84 & .84 & .81 \\
\hline 2009 & 5,441 & .83 & .85 & .82 \\
\hline 2010 & 6,068 & .83 & .84 & .81 \\
\hline 2011 & 8,846 & .84 & .84 & -- \\
\hline
\end{tabular}

Survey response rate. At the individual level, survey participation was measured by whether or not an individual participated in the survey. Survey participation is defined as an individual's decision to partake in a survey (Mertler, 2003). In aggregate, survey response rate was used to calculate the participation for a responding unit (department). Survey response rate is defined as the number of completed surveys divided by the number of eligible responding units in a sample (Skalland, 2011; Wiseman, F., \& Billington, 1984). In this study, survey response rate was measured for each group (department) using the number of complete surveys divided by the number of eligible participants invited for that particular group. The eligible number of participants invited did not include participants whose information was suppressed.

Union membership. Union membership is defined as belonging to an organization that protects employees' and bargains with the employers on the employees' behalf. Prior to survey administration, the organization provided the vendor with 
information about every eligible employee, including whether the employee was a union member. This was used to determine union membership at the participant level. At the aggregate level, percent of union membership was calculated using group (department) sum of union members divided by the total number of completed surveys. The total number of completed surveys did not include participants whose information was suppressed.

\section{Procedures}

On behalf of the organization, a third-party vendor conducted the employee engagement surveys. Prior to survey administration, the organization provided the vendor with information about every employee, including whether the employee was a union member and the group (department) in which the person was employed. Next, each employee was assigned a unique identifying pin to ensure that survey responses were linked to a particular employee and employees only took the survey once. The survey administration period lasted two weeks with surveys being completed at the location and timing of the participant's choosing. All participants were invited to take the survey via email with a link to take the survey online. Online survey submissions were automatically collected upon either the participant pressing the "submit" button or completion of at least one survey question by the end of administration period.

In addition to the online survey administration, a subgroup of participants also received a paper copy of the survey with a unique identifying pin and barcode to link survey responses to a particular employee. This subgroup was identified as employees with limited access to Internet connection, consisting mainly of a subset of unionized 
workers. Paper survey participants were given time at work to complete the survey from management. The vendor provided paper survey participants with preprinted envelopes for survey submission. Paper surveys were collected during and after the two-week administration period, and were counted as valid submissions if they were post marked by three weeks after the beginning of survey administration. If participants in the paper submission group also submitted their responses online, only one survey submission was counted (the most complete). Paper surveys that came back missing the unique identifying information could not have employee information linked to the survey responses and were assigned to an "unidentified" group. Once paper surveys were received, the third party vendor cleaned and coded the data.

After the returned surveys were compiled, the vendor created a database that mapped survey responses with union membership and group (department) assignment. Prior to the researcher receiving the data set, the third party vendor removed any identifying information, such that no specific individual could be linked to his or her survey response or union membership. With permission of the organization, the third party vendor provided the data set to the researcher. 


\section{Results}

\section{Descriptive Statistics}

The unit of analysis was at the group level $(N=180)$, rather than the individual level. Analyses were conducted for two different groups. The first group consisted of groups with 250 or fewer employees $(n=144)$ and the second group consisted of groups with greater than 250 employees $(n=36)$. These groups represented small groups in the organization that performed work different from the large groups. On one hand, small groups performed work that was more centralized in nature and work was typically in the same geographic location. On the other hand, large groups performed work that was decentralized and work was performed in many different geographic locations. Another major difference between the two groups was that small groups mostly performed work in a corporate setting, whereas large groups mostly performed work in a field setting. For these reasons, separate analyses were conducted for small and large groups.

Small groups descriptive statistics. The first set of analyses examined groups with 250 or fewer participants $(n=144)$. Mean engagement dimension scores ranged from 3.62 to 3.98 . The highest scoring dimension was dedication $(M=3.98, S D=.25)$, followed by absorption $(M=3.65, S D=.26)$ and vigor $(M=3.62, S D=.27)$. On average, $60 \%$ of individuals in groups were union members $(M=.60, S D=.47)$. The average group survey response rate was neither high nor low $(M=.51, S D=.19)$. 
Table 4

\begin{tabular}{ccc}
\multicolumn{3}{c}{ Descriptive Statistics for Groups Less than or Equal to $250(n=144)$} \\
\hline Variable & Mean & SD \\
\hline Vigor & 3.62 & .27 \\
Dedication & 3.98 & .25 \\
Absorption & 3.65 & .26 \\
Union Membership & .60 & .47 \\
Survey Response Rate & .51 & .19 \\
\hline
\end{tabular}

Large groups descriptive statistics. The second set of analyses examined groups with greater than 250 participants $(n=36)$. Mean engagement dimension scores ranged from 3.61 to 3.95. The highest scoring dimension was dedication $(M=3.95, S D=$ $.21)$, followed by absorption $(M=3.67, S D=.27)$ and vigor $(M=3.61, S D=.18)$. One key difference between the two groups is that on average $87 \%$ of participants in the large groups were union members $(M=.87, S D=.27)$. Large groups also had a higher average survey response rate $(M=.68, S D=.12)$ than small groups.

Table 5

Descriptive Statistics for Groups Greater than $250(n=36)$

\begin{tabular}{lcc}
\hline Variable & Mean & $S D$ \\
\hline Vigor & 3.61 & .18 \\
Dedication & 3.95 & .21 \\
Absorption & 3.67 & .27 \\
Union Membership & .87 & .27 \\
Survey Response Rate & .68 & .12 \\
\hline
\end{tabular}

Group comparisons. There were some similarities and differences between the small and large groups. Interestingly, both small groups and large groups had similar mean scores for vigor, dedication, and absorption. This implies that employee engagement levels did not differ as a function of group size. However, small groups and 
large groups differed in mean union membership rates and survey response rates. On average, large groups had higher union membership rates and had higher survey participation rates than small groups. This means that large groups had more union members and, in general, had more employees voluntarily participate in the survey compared to small groups.

\section{Pearson Correlations}

Small groups correlations. Pearson correlations were conducted to examine the relationships between the predictors and the moderating variable with the criterion. For groups with 250 or fewer participants, vigor, dedication, and absorption were all significantly and positively related to survey response rate (see Table 6). Groups that had higher energy $(r=.23, p<.01)$, a stronger sense of pride $(r=.22, p<.01)$, and deeper engrossment with work $(r=.25, p<.01)$ had higher survey response rates. The relationships between the three dimensions and survey response rate suggest that high energy levels, strong pride, and deep engrossment with work among groups were all related to voluntary participation in surveys. Additionally, there was no significant relationship between percent of union members in a group and survey response rate ( $r=$ $-.16, p>.05)$. This implies that the amount of union membership in a group was not related to survey response rate.

Next, it is important to note significant correlations among the predictors. All three dimensions of employee engagement were significantly and positively correlated with one another. Groups that had higher energy levels also had a stronger sense of pride and significance $(r=.85, p<.001)$, and deeper engrossed with work $(r=.72, p<.001)$. 
A stronger sense of pride and significance were also related to higher enjoyment at work $(r=.84, p<.001)$. The strong correlations between predictors indicate that the three dimensions of employee engagement measured the same construct (i.e., employee engagement). The strength of these relationships also suggests that these dimensions were redundant with one another.

It is also important to note significant correlations between the moderating variable (union membership) and predictors. Union membership was significantly related to predictors for groups with 250 or fewer participants. Vigor $(r=-.67, p<.001)$ and dedication $(r=-.56, p<.001)$ were strongly and negatively related to union membership, whereas absorption was moderately negatively related to union membership $(r=-.37 p<.001)$. Groups with a higher percentage of union membership were less likely to experience engagement at work than groups with a lower percentage of union membership. The relationship between vigor and union membership suggests that groups with a higher percentage of union membership were more likely than groups with a lower percentage of union membership to have a less enthusiasm or energy at work. The relationship between dedication and union membership implies that groups with a higher percentage of union membership were less likely than groups with a lower percentage of union membership to have a strong sense of pride about the organization, or to be involved in extra organizational activities. Lastly, the relationship between absorption and union membership implies that groups with a higher percentage of union membership had greater difficultly focusing and did not enjoy completing tasks while at work than groups with a lower percentage of union membership. 
Table 6

Intercorrelations Matrix for Groups Less than or Equal to $250(n=144)$

\begin{tabular}{lccccc}
\hline \multicolumn{1}{c}{ Variable } & 1 & 2 & 3 & 4 & 5 \\
\hline 1 Dimension: Vigor & -- & & & \\
2 Dimension: Dedicatior & $.85 * * *$ & -- & & \\
3 Dimension: Absorptio1 & $.72 * * *$ & $.84 * * *$ & -- & & \\
4 Union Membership & $-.67 * * *$ & $-.56 * * *$ & $-.37 * * *$ & -- & - \\
5 Survey Response Rate & $.23 * *$ & $.22 * *$ & $.25 * *$ & -.16 & \\
\hline$* * p \leq .01 ; * * p \leq .001$ & & & & &
\end{tabular}

Large groups correlations. Pearson correlations were also conducted for groups with greater than 250 participants. Examining relationships with the criterion, vigor, dedication, and absorption were all found to be significantly and positively related to survey response rate (see Table 7). Survey response rates were higher when groups had higher energy levels $(r=.65, p<.001)$, a stronger sense of personal accomplishment or pride $(r=.56, p<.001)$, and experienced deeper engrossment with work $(r=.57, p<$ $.001)$. This suggests that engaged groups were likely to voluntarily participate in surveys. Examining the relationship between the moderator (union membership) and survey response rate, there was no significant relationship $(r=-.06, p>.05)$. This implies that the percent of union membership in a group was not related to survey response rate.

Furthermore, all three dimensions of engagement were also significantly and positively correlated with one another. Groups that had higher energy levels also had a stronger sense of pride and significance $(r=.74, p<.001)$. Moreover, groups with 
higher energy levels were also deeply engrossed with work $(r=.67, p<.001)$. Groups that had a stronger sense of pride and significance also had a deeper state of engrossment with work $(r=.93, p<.001)$. It is important to note that this relationship was strong, indicating that these two dimensions were redundant with one another. Lastly, it is important to note correlations between union membership and predictors. Unlike small groups, there were no significant correlations between predictors and union membership for large groups, suggesting that group engagement levels and the percentage of union membership were not related.

Table 7

Intercorrelations Matrix for Groups Greather than $250(n=36)$ Variable

$1 \quad 2 \quad 3$

4

5

1 Dimension: Vigor $--$

2 Dimension: Dedication

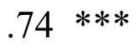

3 Dimension: Absorption

.67

$* * *$

.93

4 Union Membership

$-.27$

.23

.32

5 Survey Response Rate

.65

.56

$.57 * * *$

$-.06$

$* * * p \leq .001$

Group comparisons. Comparing small and large groups, the relationships between the dimensions of engagement and survey response rate were stronger for groups with greater than 250 participants. This suggests that there were stronger relationships between energy levels, pride, and work engrossment with survey response rate for large groups compared to small groups. For both groups, there was no significant relationship between union membership and survey response rate. Additionally, high energy levels, a 
strong sense of pride, and deep engrossment with work were all related to one another for both small and large groups. In particular, pride and engrossment with work were strongly related to one another for large groups. Lastly, one major difference between small and large groups was that the relationship between union membership and survey response rate was only significant for small groups. This implies that the relationship between the percentage of union membership for a group and survey response rate only existed for groups with 250 or fewer participants.

\section{Standard Multiple Regression Analyses}

Hypothesis 1 stated that employee engagement would be positively related to survey response rate. To test this hypothesis, a standard multiple regression analysis was conducted to examine the predictive value of the three dimensions of employee engagement (vigor, dedication, and absorption).

Small groups analysis. For groups with 250 or fewer participants, the three dimensions of employee engagement were entered as a set and were significantly related to survey response rate (see Table 8 ). The three dimensions accounted for $7 \%$ of variance in survey response rate $\left(\mathrm{R}=.26, \mathrm{R}^{2}=.07, \mathrm{R}^{2} \mathrm{adj}=.05, F(3,140)=3.43, p<.05\right)$. Examining the three dimensions of engagement more closely, none of the dimensions of employee engagement had a significant unique relationship with survey response rate. Given that the overall relationship was significant, the predictors had non-significant betas likely due to multicollinearity. In other words, the predictors were highly correlated, and therefore redundant, with one another. Furthermore, there was a negative beta for dedication, suggesting that groups with a stronger sense of pride and significance 
had lower survey response rates. Comparing the negative beta of dedication with its positive correlation with survey response rate $(r=.22)$ suggests that dedication was a suppressor variable due to its strong correlation with absorption $(r=.84)$. Thus, the negative beta of dedication should be considered a statistical artifact rather than an interpretable and meaningful effect. Thus Hypothesis 1 was supported for small groups, such that groups with higher energy levels, a stronger sense of pride, and deeper engrossment were related to higher survey response rates.

Table 8

Standard Multiple Regression Analysis: Prediction of Survey Response Rate by Vigor, Dedication, and Absorption for Groups Less than or Equal to $250 \quad(n=144)$

\begin{tabular}{lcc}
\hline \multicolumn{1}{c}{ Variable } & $\beta$ & $\mathrm{sr}$ \\
\hline Block 1: Dimensions of Engagement & & \\
Vigor & .17 & .09 \\
Dedication & -.10 & -.04 \\
Absorption & .20 & .11 \\
\hline
\end{tabular}

Large groups analysis. For groups with more than 250 participants, the three dimensions of employee engagement were also entered as a set and were significantly related to survey response rate (see Table 9). Vigor, dedication, and absorption accounted for $46 \%$ of variance in survey response rate $\left(\mathrm{R}=.68, \mathrm{R}^{2}=.46, \mathrm{R}^{2} \mathrm{adj}=.41\right.$, $F(3,32)=9.17, p<.001)$. This is a much stronger effect than the effect found for small groups. Only vigor had a significant unique relationship with survey response rate $(\beta=$ $.54, t=2.78, p<.01)$, indicating that groups with higher energy levels and higher numbers of voluntary behaviors had higher survey response rates. Like small groups, the beta for dedication was negative, whereas the correlation between dedication and 
absorption were positive, indicating that dedication was a suppression variable. Once again, Hypothesis 1 was supported for large groups, such that groups with higher employee engagement level also had higher survey response rates.

Table 9

Standard Multiple Regression Analysis: Prediction of Survey Response Rate by Vigor, Dedication, and Absorption for Groups Greater than $250 \quad(n=36)$

\begin{tabular}{ccc}
\hline \multicolumn{1}{c}{ Variable } & $\beta$ & $\mathrm{sr}$ \\
\hline Block 1: Dimensions of Engagement & & \\
Vigor & $.54 * *$ & .36 \\
Dedication & -.22 & -.07 \\
Absorption & .41 & .15 \\
\hline$* * p \leq .01$ & &
\end{tabular}

Group comparisons. In summary, for both groups, groups with more engaged employees had higher survey participate rates. The difference in the explained variance between the two groups (small and large) suggests that group size might moderate the relationship between employee engagement and survey response rate, such that the relationship was stronger for large groups. Furthermore, there were no significant individual predictors for small groups; however, there was a significant relationship between vigor and survey response rate for large groups. This implies that the relationships between predictors and survey response rate were stronger for large groups. Moreover, for both small and large groups, the negative betas for dedication and positive correlations between dedication and absorption suggest that dedication was a suppressor variable. In conclusion, for both small and large groups, results supported Hypothesis 1, 
such that groups with higher energy levels, a stronger sense of pride, and deeper engrossment with work had higher survey response rates.

\section{Hierarchical Multiple Regression Analyses}

Hypothesis 2 stated that union membership would moderate the relationship between employee engagement and survey response rate, such that the relationship between engagement and survey response rate would be stronger when union membership was high than when it was low. To test this hypothesis, three separate hierarchical multiple regression analyses were conducted to examine the predictive value of union membership, above and beyond the three engagement dimensions.

Small groups analyses. The first set of analyses examined the moderating effect of union membership for groups with 250 or fewer participants. The first hierarchical multiple regression analysis was conducted to examine the moderating effect of union membership on the relationship between vigor and survey response rate. Vigor was entered in Step 1, union membership was entered in Step 2, and the cross product of vigor and union membership was entered in Step 3 (see Table 10). In Step 1, vigor accounted for $6 \%$ of the variance in survey response rate $\left(\mathrm{R}^{2}=.06, \mathrm{R}^{2} \mathrm{adj}=.05, F(1,142)=8.22, p<\right.$ $.01)$. Groups that had higher energy levels and resilience had higher survey participation rates than groups with lower energy levels and resilience. In Step 2, union membership and vigor accounted for $6 \%$ of the variance in survey response rate $\left(\mathrm{R}^{2}=.06, \mathrm{R}^{2} \mathrm{adj}=.04\right.$, $F(2,141)=4.08, p<.05)$. However, there was no significant incremental value of union membership $\left(\Delta \mathrm{R}^{2}=.00, \Delta F(1,141)=.00, p>.05\right)$. Although the overall relationship was significant, union membership did not add any predictive value to the relationship 
between energy levels and survey response rate. In Step 3, the cross product of union membership and vigor, union membership, and vigor accounted for $6 \%$ of the variance in survey response rate $\left(\mathrm{R}^{2}=.06, \mathrm{R}^{2} \mathrm{adj}=.04, F(3,140)=3.02, p<.05\right)$. However there was no significant incremental value of the cross product of union membership and vigor on survey response rate $\left(\Delta \mathrm{R}^{2}=.00, \Delta F(1,140)=.90, p>.05\right)$ above and beyond that of union membership and vigor. This suggests that union membership did not moderate the relationship between vigor and survey response rate.

Table 10

Hierarchical Multiple Regression Analysis: Prediction of Survey Response Rate by Vigor and Union Membership for Groups Less than or Equal to 250 ( $n=144)$

\begin{tabular}{|c|c|c|c|}
\hline Variable & $\mathrm{sr}$ & $\mathrm{R}^{2}$ & $\Delta \mathrm{R}^{2}$ \\
\hline Block 1 & & & \\
\hline Vigor & .23 & $.06 * *$ & \\
\hline
\end{tabular}

Block 2

Union Membership

$-.01 \quad .06 *$

.00

Block 3

Vigor x Union Membership (crossproduct)

$\begin{array}{ll}-.08 & .06 *\end{array}$

.00

$* p \leq .05 ;{ }^{* *} p \leq .01$

A second hierarchical multiple regression analysis was conducted to examine the moderating effect of union membership on the relationship between dedication and survey response rate. In this analysis, dedication was entered in Step 1, union membership was entered in Step 2, and the cross product of dedication and union membership was entered in Step 3 (see Table 11). In Step 1, dedication accounted for $5 \%$ of variance in survey response rate $\left(\mathrm{R}^{2}=.05, \mathrm{R}^{2} \mathrm{adj}=.04, F(1,142)=7.02, p<.01\right)$. Groups with a stronger sense of pride and personal significance at work had higher 
survey response rates than groups with a lower sense of pride or significance. In Step 2, dedication and union membership accounted for $5 \%$ of variance in survey response rate $\left(\mathrm{R}^{2}=.05, \mathrm{R}^{2} \mathrm{adj}=.04, F(2,141)=3.66, p<.05\right)$. Although the overall relationship was significant, the percentage of union membership in a group did not add any predictive value to the relationship between pride and personal accomplishment with survey participation behavior. Union membership did not have a significant incremental effect, above and beyond dedication $\left(\Delta \mathrm{R}^{2}=.00, \Delta F(1,141)=.34, p>.05\right)$. In Step 3 , the cross product of union membership and dedication, union membership, and dedication accounted for $8 \%$ of variance in survey response rate $\left(\mathrm{R}^{2}=.08, \mathrm{R}^{2} \mathrm{adj}=.06, F(3,140)=\right.$ $3.86, p<.05)$. The cross product of union membership and dedication also had a significant incremental effect, above and beyond union membership and dedication $\left(\Delta \mathrm{R}^{2}\right.$ $=.03, \Delta F(1,140)=4.09, p<.05)$. This indicates that union membership moderated the relationship between dedication and survey response rate.

Table 11

Hierarchical Multiple Regression Analysis: Prediction of Survey Response Rate by Dedication and Union Membership for Groups Less than or Equal to $250(n=144)$

\begin{tabular}{cccc}
\hline \multicolumn{1}{c}{ Variable } & $\mathrm{sr}$ & $\mathrm{R}^{2}$ & $\Delta \mathrm{R}^{2}$ \\
\hline Block 1 & & & \\
Dedication & .22 & $.05 * *$
\end{tabular}

Block 2

Union Membership

$-.05 \quad .05 *$

.00

Block 3

Dedication x Union

Membership (crossproduct)

$-.16 \quad .08 * *$

$.03 *$

$* p \leq .05 ; * * p \leq .01$ 
Two standard regression analyses were conducted to examine the relationship between dedication and survey response rate for groups with "low" and "high" union membership (see Figure 1). Low and high union membership were determined by calculating the median value for percentage of union membership. Groups that were less than the median were put in the low union membership group, and groups that were equal to or above the median were put in the high union membership group. The relationship between dedication and survey response rate was significantly and positively stronger when union membership was low $\left(\mathrm{R}^{2}=.10, \mathrm{R}^{2} \mathrm{adj}=.09, F(1,69)=7.86, p<.01\right)$ than when union membership was high $\left(\mathrm{R}^{2}=.00, \mathrm{R}^{2} \mathrm{adj}=-.01, F(1,71)=.01, p>.05\right)$. This partially supports Hypothesis 2, however, high union membership did not increase the strength of the relationship between dedication and survey response rate as predicted. Rather, union membership moderated the relationship between dedication and survey response rate such that it nullified the relationship. When union membership was low, there was a strong positive relationship between dedication and survey response rate. In other words, when the percent of union membership was low, highly dedicated groups had higher survey response rates. However, when percent of union membership was high, there was no relationship between dedication and survey response rate. That is, a high percentage of union membership did not influence the relationship between having a sense of pride or personal accomplishment and survey response rate. 


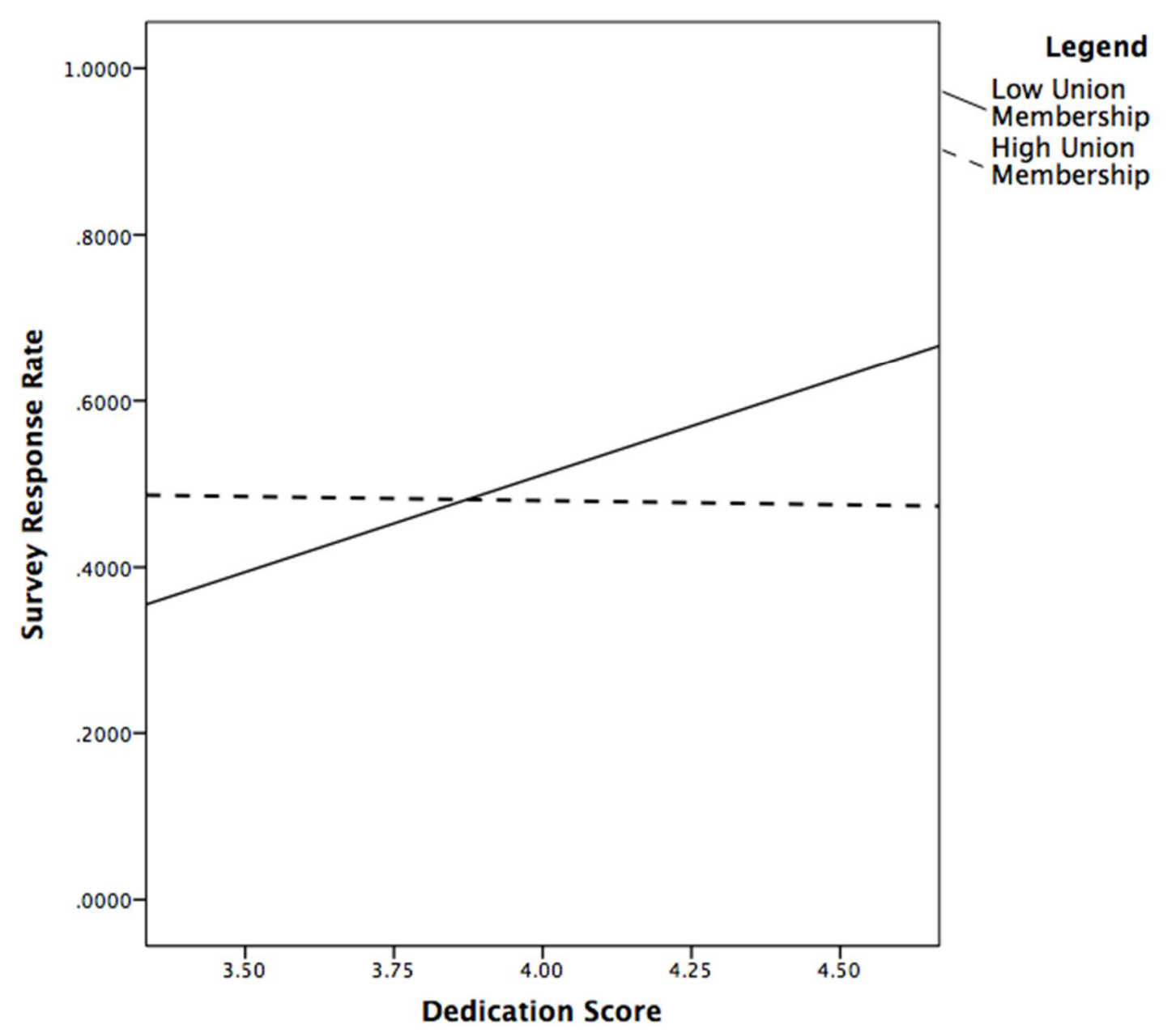

Figure 1. Interaction effects of dedication on survey response rate for groups less than or equal to $250(n=144)$.

Lastly, a third hierarchical multiple regression analysis was conducted to examine the moderating effect of union membership on the relationship between absorption and survey response rate. Absorption was entered in Step 1, union membership was entered in Step 2, and the cross product of union membership and absorption was entered in Step 3 (see Table 12). In Step 1, absorption accounted for 6\% of variance in survey response rate $\left(\mathrm{R}^{2}=.06, \mathrm{R}^{2} \mathrm{adj}=.05, F(1,142)=9.08, p<.01\right)$. Groups that had deeper engrossment with work were more likely to have higher survey response rates than 
groups that were not engrossed. In Step 2, absorption and union membership accounted for $7 \%$ of variance in survey response rate $\left(\mathrm{R}^{2}=.07, \mathrm{R}^{2} \mathrm{adj}=.05, F(2,141)=4.97, p<\right.$ $.01)$. Union membership $\left(\Delta \mathrm{R}^{2}=.01, \Delta F(1,141)=.87, p>.05\right)$ did not have a significant incremental effect on survey response rate, above and beyond absorption. Percentage of union membership in a group did not add any predictive value to the relationship between deep engrossment with work and survey response rate. In Step 3, the cross product of union membership and absorption, union membership, and absorption accounted for $9 \%$ of variance in survey response rate $\left(\mathrm{R}^{2}=.09, \mathrm{R}^{2} \mathrm{adj}=.07, F(3,140)=4.65, p<.01\right)$. However, the cross product of union membership and absorption $\left(\Delta \mathrm{R}^{2}=.02, \Delta F(1,140)=\right.$ $3.82, p>.05)$ did not have an incremental effect on survey response rate, above and beyond union membership and absorption. This indicates that percentage of union membership in a group did not moderate the relationship between deep engrossment with work and survey response rate.

Table 12

Hierarchical Multiple Regression Analysis: Prediction of Survey Response Rate by Absorption and Union Membership for Groups Less than or Equal to $250(n=144)$

\begin{tabular}{|c|c|c|c|}
\hline Variable & $\mathrm{sr}$ & $\overline{\mathrm{R}^{2}}$ & $\overline{\Delta \mathrm{R}^{2}}$ \\
\hline \multicolumn{4}{|l|}{ Block 1} \\
\hline Absorption & .25 & $.06 * *$ & \\
\hline \multicolumn{4}{|l|}{ Block 2} \\
\hline Union Membership & -.08 & $.07 * *$ & .01 \\
\hline \multicolumn{4}{|l|}{ Block 3} \\
\hline $\begin{array}{l}\text { Absorption x Union } \\
\text { Membership (crossproduct) }\end{array}$ & -.16 & $.09 * *$ & .02 \\
\hline
\end{tabular}

$* * p \leq .01$ 
Large groups analyses. The second set of analyses examined the moderating effect of union membership for groups that had more than 250 participants. The first hierarchical multiple regression analysis was conducted to examine the moderating effect of union membership on the relationship between vigor and survey response rate. Vigor was entered in Step 1, union membership was entered in Step 2, and the cross product of vigor and union membership was entered in Step 3 (see Table 13). In Step 1, vigor accounted for $43 \%$ of the variance in survey response rate $\left(\mathrm{R}^{2}=.43, \mathrm{R}^{2} \mathrm{adj}=.41, F(1,34)\right.$ $=25.17, p<.001)$. For large groups, there was a much stronger relationship between high energy levels and resilience and survey response rate than small groups. In Step 2, union membership and vigor accounted for $44 \%$ of the variance in survey response rate $\left(\mathrm{R}^{2}=.44, \mathrm{R}^{2} \mathrm{adj}=.41, F(2,33)=12.99, p<.001\right)$. However, there was no significant incremental value of union membership $\left(\Delta \mathrm{R}^{2}=.01, \Delta F(1,33)=.89, p>.05\right)$, above and beyond that of vigor. Percentage of union membership did not add any predictive value to the relationship between high energy levels and survey response rate. In Step 3, the cross product of union membership and vigor, union membership, and vigor accounted for $44 \%$ of the variance in survey response rate $\left(\mathrm{R}^{2}=.44, \mathrm{R}^{2} \mathrm{adj}=.39, F(3,32)=8.42, p<\right.$ .001). However there was no significant incremental value of the cross product of union membership and vigor on survey response rate $\left(\Delta \mathrm{R}^{2}=.00, \Delta F(1,32)=.04, p>.05\right)$ above and beyond that of union membership and vigor. This suggests that the relationship between energy levels and survey response rate did not differ due to percentage of union membership. 
Table 13

Hierarchical Multiple Regression Analysis: Prediction of Survey Response Rate by Vigor and Union Membership for Groups Greater than $250(n=36)$



Block 2

Union Membership

.12

$.44 * * *$

.01

Block 3

Vigor x Union Membership (crossproduct)

$.44 * * *$

.00

$* * * p \leq .001$

Next, a second hierarchical multiple regression analysis was conducted to examine the moderating effect of union membership on the relationship between dedication and survey response rate. Dedication was entered in Step 1, union membership was entered in Step 2, and the cross product of union membership and dedication was entered in Step 3 (see Table 14). In Step 1, dedication accounted for 32\% of variance in survey response rate $\left(\mathrm{R}^{2}=.32, \mathrm{R}^{2} \mathrm{adj}=.30, F(1,34)=15.85, p<.001\right)$. Groups with a stronger sense of pride and personal significance at work had higher survey response rates than groups with a weaker sense of pride and significance. In Step 2, dedication and union membership accounted for $36 \%$ of variance in survey response rate $\left(\mathrm{R}^{2}=.36, \mathrm{R}^{2} \mathrm{adj}=.32, F(2,33)=9.13, p=.001\right)$. Union membership did not have a significant incremental effect, above and beyond dedication $\left(\Delta \mathrm{R}^{2}=.04, \Delta F(1,33)=1.96\right.$, $p>.05)$. Percentage of union membership in a group did not add any predictive value to the relationship between a strong sense of pride and personal significance and survey response rate. In Step 3, the cross product of union membership and dedication, union 
membership, and dedication accounted for $37 \%$ of variance in survey response rate $\left(\mathrm{R}^{2}=\right.$ $\left..37, \mathrm{R}^{2} \mathrm{adj}=.32, F(3,32)=6.36, p<.01\right)$. The cross product of union membership and dedication did not have a significant incremental effect, above and beyond union membership and dedication $\left(\Delta \mathrm{R}^{2}=.01, \Delta F(1,32)=.89, p<.05\right)$. In summary, dedication, union membership, and the cross product of union membership and dedication explained approximately two-fifths of variance in survey response rate. However, there was no significant moderating effect of the percentage of union membership in a group.

Table 14

Hierarchical Multiple Regression Analysis: Prediction of Survey Response Rate by Dedication and Union Membership for Groups Greater than $250 \quad(n=36)$

\begin{tabular}{llll}
\hline \multicolumn{1}{c}{ Variable } & $\mathrm{sr}$ & $\mathrm{R}^{2}$ & $\Delta \mathrm{R}^{2}$ \\
\hline Block 1 & & & \\
Dedication & .56 & $.32^{* * *}$ & \\
Block 2 & & & .04 \\
$\quad$ Union Membership & -.20 & $.36^{* * *}$ & .01 \\
Block 3 & & & \\
$\quad \begin{array}{l}\text { Dedication x Union } \\
\text { Membership (crossproduct) }\end{array}$ & -.13 & $.37^{* *}$ &
\end{tabular}

Lastly, a third hierarchical multiple regression analysis was conducted to examine the moderating effect of union membership on the relationship between absorption and survey response rate. Absorption was entered in Step 1, union membership was entered in Step 2, and the cross product of union membership and absorption was entered in Step 3 (see Table 15). In Step 1, absorption accounted for 32\% of variance in survey response rate $\left(\mathrm{R}^{2}=.32, \mathrm{R}^{2} \mathrm{adj}=.30, F(1,34)=16.20, p<.001\right)$. In Step 2, absorption and union 
membership accounted for $39 \%$ of variance in survey response rate $\left(R^{2}=.39, R^{2}\right.$ adj $=$ $.35, F(2,33)=10.50, p<.001)$. Union membership $\left(\Delta \mathrm{R}^{2}=.07, \Delta F(1,33)=3.58, p>.05\right)$ did not have a significant incremental effect on survey response rate, above and beyond absorption. In Step 3, the cross product of union membership and absorption, union membership, and absorption accounted for $41 \%$ of variance in survey response rate $\left(\mathrm{R}^{2}=\right.$ $\left..41, \mathrm{R}^{2} \mathrm{adj}=.36, F(3,32)=7.54, p=.001\right)$. However, the cross product of union membership and absorption $\left(\Delta \mathrm{R}^{2}=.02, \Delta F(1,32)=1.37, p>.05\right)$ did not have an incremental effect on survey response rate, above and beyond union membership and absorption. This indicates that the relationship between absorption and survey response rate did not differ as a function of the percentage of union membership in a group.

Table 15

Hierarchical Multiple Regression Analysis: Prediction of Survey Response Rate by Absorption and Union Membership for Groups Greater than $250 \quad(n=36)$

\begin{tabular}{cccc}
\hline \multicolumn{1}{c}{ Variable } & $\mathrm{sr}$ & $\mathrm{R}^{2}$ & $\Delta \mathrm{R}^{2}$ \\
\hline Block 1 & & & \\
Absorption & .57 & $.32 * * *$ &
\end{tabular}

Block 2
Union Membership
$-.26$
$.39^{* * *}$
.07

Block 3

Absorption x Union

Membership (crossproduct)

$-.16 \quad .41 * * *$

.02

$* * * p \leq .001$

Group comparisons. For both small and large groups, there were significant relationships between the three engagement dimensions and survey response rate. Additionally, union membership had no incremental effect on the relationship between employee engagement and survey response rate. This could be due to multicollinearity of 
variables. Lastly, with one exception, percentage of union membership did not moderate the relationship between engagement and survey response rate for both groups. Only small groups had a significant interaction effect between dedication and union membership. Groups that had a lower percentage of union membership had a stronger sense of pride and significance and higher survey response rates than groups with a high percentage of union membership. The more dedicated groups were, the more likely they were to participate in survey when the percentage of union members was low. 


\section{Discussion}

Employee engagement is a topic of particular interest to organizations and researchers. Research has demonstrated employee engagement to be related to many organizational outcomes, such as productivity, low turnover, and organizational citizenship behaviors (Gallup, 2012; Cowart et al., 2013; Rich et al., 2010). Furthermore, organizations are interested in having high employee participation in organizational surveys. With regard to employee engagement, survey participation represents a behavior that employees can voluntarily choose to engage in. However, the relationship between employee engagement and survey participation behavior has not been examined, nor have factors that influence the strength of this relationship. In unionized industries, there is also much interest in how union membership affects the relationship between employee engagement and survey participation behavior. Hence, the purpose of the present study was to examine the relationship between employee engagement and survey response rate, and how that relationship varied as a function of union membership.

\section{Summary of Results}

Analyses were conducted at the aggregate level, looking at two different group sizes to examine group differences. The first grouping, small groups, consisted of groups with 250 or fewer employees. The second grouping, large groups, consisted of groups with greater than 250 employees. Smaller groups represented groups in the organization that performed centralized work, whereas large groups represented groups in the organization that performed decentralized work. Another major distinction between groups was that smaller groups tended to perform work in a corporate setting, and larger 
groups tended to perform work in a field setting. In general, both small and large groups had high mean levels for each dimension of engagement; energy levels, a sense of pride and significance, and for engrossment with work. However, larger groups had a greater number of employees participate in the survey and a greater number of unionized employees than smaller groups.

Relationships between variables. For both small and large groups, the relationship between energy levels, pride, and engrossment with work were all positively related to survey response rate. However, the relationships were stronger for larger groups than smaller groups. Also, union membership was not related to survey response rate for either group, implying that the percentage of union membership in a group was not associated with survey response rate. For both small and large groups, the dimensions of engagement were highly correlated with one another, suggesting that the all three dimensions measured the same construct and were possibly redundant with each other. For small groups, the strongest relationships were between high energy levels and a strong sense of pride or significance, and a strong sense of pride or significance and engrossment with work. For large groups, the strongest relationship was between a strong sense of pride or significance and deep engrossment with work. One major difference between groups was that the relationship between union membership and predictors was only significant for small groups. This suggests that in groups with 250 or fewer participants, vigor, dedication, and absorption were related to survey response rate.

The relationship between employee engagement and survey response rate. Two regression analyses were conducted to examine the relationship between employee 
engagement and survey response rate at group level. For both small and large groups, employee engagement predicted survey response rates. Groups that had higher energy levels and more resilient, had a stronger sense of pride and personal accomplishment, and deeper engrossment with work were more likely to have higher survey response rates than less engaged groups. However, this relationship was much stronger for larger groups than smaller groups. Engaged groups were more likely to have higher response rates for organizational surveys in large groups compared to small groups possibly due to the survey administration method. All employees were invited to participate in the survey online via email. However, a subgroup of individuals who were union members was also invited to take the survey via paper. Larger groups had a larger percentage of unionized employees who had two chances to take the survey, compared to non-union employees who were only invited to take the survey online.

It is important to note that, among the engagement dimensions, only vigor was uniquely related to survey response rate for large groups. Given that all of the engagement dimensions were individually related to survey response rate, the lack of significant unique relationships for dedication and absorption was probably due to multicollinearity between these predictors. This means that energy at work, pride, and engrossment with work were all highly related, and therefore redundant, with one another. This overlap between engagement dimensions explains why the unique relationship between dedication and survey response rate, albeit not significant, was found to be negative for both small and large groups even though its individual relationship was positive. 


\section{The moderating effect of union membership on the relationship between}

employee engagement and survey response rate. For large groups, the percentage of union membership in a group did not influence the relationship between energy at work, pride, and engrossment with work and survey response rate. This suggests that the relationship between employee engagement and survey response rate did not depend on union membership. Regardless of the percentage of union membership, engaged groups were more likely to participate in the survey than less engaged employees. Given that the size of the sample for large groups was small, it is not a surprise that no significant moderating effect was found.

For small groups, union membership only influenced the relationship between dedication (having a sense of pride and personal accomplishment at work) and survey response rate. The relationship between dedication and survey response rate was influenced by percentage of union membership, such that a high percentage of union membership nullified the relationship between the variables. When percentage of union membership was low, groups with a stronger sense of pride were more likely to participate in the survey than less engaged groups. When percentage of union membership was high, engaged groups with a sense of pride and disengaged groups without a sense of pride were equally likely to participate in the survey. However, no moderating effect was found for the relationship between energy and survey response rate, or for the relationship between engrossment with work and survey response rate.

\section{Implications}


Theoretical implications. The results of the present study confirm previous research regarding the relationship between engagement and voluntary behaviors in the workplace (Rich et al., 2010). The present study shows such a relationship at group level. Like previous research, engaged groups were more likely than disengaged groups to engage in the voluntary behavior being measured (survey response rate). In addition, the results of this study partially align with previous research on the influence of a union variable on the relationship between psychological predictors and behavioral outcomes (Bulger, 2001; Mellor \& Golay, 2014). Previous research found that union variables weakened the relationship between a negative psychological predictor and negative behavioral outcome. In examining the relationship between a positive predictor (engagement) and a positive outcome (survey response rate), one significant moderating effect was found on the relationship between dedication and survey participation for small groups. Moreover, results conflict with the hypothesis that union variable would strengthen the relationship between a positive predictor and a positive outcome (Hypothesis 2), suggesting that percentage of union membership in a group can weaken the positive relationship between employee engagement and survey participation for organizations.

One critical theoretical implication of this study is that group size influenced the relationship between employee engagement and survey response rate, such that the relationship was stronger for larger groups. This finding is contrary to previous research, which suggested that group size did not influence survey response rate (Baruch \& Holtom, 2008). This suggests that the size of a work group may play a critical role in the 
relationship between engagement and positive work outcomes, and to a lesser degree the moderating effect of union membership.

Practical implications. One important question that organizations should be asking is what the engagement levels of employees who do not participate in employee engagement surveys are. The results of this study indicate that there is a positive relationship between group engagement and survey response rate, suggesting that one reason for a lack of survey participation might be disengagement from work. Groups that are energized by their work, are more willing to engage in more extra-role behaviors, feel a sense of pride, and enjoy their work are more likely to have higher survey response rates than disengaged groups. However, the strength of this relationship is weaker for smaller groups than larger groups, suggesting that smaller groups should possibly put interventions (action plans) into place to increase engagement levels for group members.

From a group perspective, survey participation indicated the engagement level of employees for that particular group. Lower group survey participation was linked to lower energy levels, a lower sense of pride or personal accomplishment at work, and a lower sense of engrossment with work. Research has demonstrated that employees who are disengaged are more likely to engage in unwanted behaviors, such as theft, absenteeism, and attrition (Cowart, Crowell, \& Kaye, 2013; Gallup, 2012; Modern Survey, 2013). Additionally, having disengaged employees can erode the beneficial actions and attitudes of engaged employees (Maslach, Schaufeli, \& Leiter, 2001). From a group and organizational perspective, lower survey participation may be indicative of lower engagement levels. In other words, it might be another diagnostic tool (along with 
employee engagement scores) for identifying groups where cultural and organizational changes need to occur.

\section{Contributions of the Current Study}

The present study was the first study to examine the relationship between employee engagement and survey response rate at the group level. This study introduces voluntary employee survey participation (survey response rate) as a possible index of group employee engagement levels. This is particularly interesting given that engagement levels cannot be known for survey non-participants. In a way, survey nonparticipation could indicate intentional sabotage behaviors that employees engage in when they are disengaged, or employees who are in a state of disengagement.

Moreover, the present study was the first study to examine factors that may influence the relationship between employee engagement and survey response rate. In unionized industries, the influence of union membership on employee engagement and survey participation is a particular topic of interest for organizations. In the present study, percentage of union membership for a group only influenced the relationship between having a strong sense of pride and personal accomplishment and survey response rate in small groups.

\section{Limitations and Future Research}

One major limitation of the present study was that predictors were highly correlated with one another. This is a concern because it likely limited the unique contributions of predictors in the relationship between employee engagement and survey response rate. Moreover, the strong relationships between dimensions of engagement 
indicate redundancy. Given the high correlations between variables, further research is needed to examine how union membership influences the relationship between the dimensions of engagement and survey participation behavior.

A second limitation of the current study was that the study was conducted at a single organization in the utility industry. This may limit the generalizability of the results to other organizations or other industries. In particular the moderating variable (union membership) is only generalizable to other unionized industries, such as construction, manufacturing and transportation. Additionally, the generalizability of group findings will depend on whether or not the nature of the work is centralized or decentralized geographically speaking, and whether or not the nature of the work performed is similar to the described groups. Therefore, future research is needed to replicate the findings of (a) the relationship between employee engagement and survey response rate in other organizations and industries and (b) the moderating effect of union membership at different organizations in unionized industries.

A third limitation is the sample size used for large groups. The small size may have limited the strength and significance of relationships found. Large groups also had a higher amount of unionized employees than small groups. Further research is needed to examine how this influenced the moderation effect of union membership on the relationship between employee engagement and survey response rate with a larger sample size for large groups. Given that some of the groups were measured more than once, the assumption of the independent of observation was violated. Thus, the results should be interpreted with caution. 
Lastly, one particularly interesting finding was the non-significant negative unique relationship between dedication and survey response rate. Unlike the other dimensions of engagement, the negative relationship indicates that groups that had a sense of pride and accomplishment were less likely to participate in the survey. However, dedication was also highly correlated with absorption, indicating that it was a suppressor variable. Future research is needed to examine the nature of this relationship and why it occurred.

\section{Conclusion}

Given the many benefits of having an engaged workforce, employee engagement is an important topic of interest for organizations. Engaged employees have been found to relate to a variety of organizational outcomes, including a willingness to perform extrarole tasks. One way of measuring employee engagement is through organizational surveys. To ensure the validity of results, organizational surveys need a representative sample of the organization participate. Thus, research has examined the relationship between survey methodology and survey response rate. Survey response rate represents the aggregate of voluntary employee participation in surveys and may be an outcome of employee engagement. However, previous research has not examined the relationship between employee engagement and voluntary survey participation behavior. Moreover, research has not examined how this relationship may vary as a function of union membership. Therefore, the purpose of the present study was to address this gap in the literature and provide insight at the group level. Results revealed that there was a positive relationship between the variables, with larger groups having stronger 
relationships. This suggests that survey response rate is an indicator of group engagement levels. Survey response rate can be used as a diagnostic tool to examine engagement levels, and to a certain extent reveal disengagement at the group level. Furthermore, the relationship between pride and survey response rate was influenced by percentage of union membership in a group. However, this only occurred for small groups with 250 or fewer participants. Additional research is needed to validate the findings of the current study and further understand the moderating effect of union membership. 


\section{References}

Baruch, Y., \& Holtom, B. C. (2008). Survey response rate levels and trends in organizational research. Human Relations, 61, 1139-1160.

Bates, S. (2004, February). Getting engaged. HR Magazine, 49(2). Retrieved from: http://www.shrm.org/publications/hrmagazine/editorialcontent/pages/0204covstor y.aspx

Budd, J. W., Gollan, P. J., \& Wilkinson, A. (2010). New approaches to employee voice and participation in organizations. Human Relations 63, 303-310. doi:10.1177/0018726709348938

Brochu, P., \& Morin, L. P. (2012). Union membership and perceived job insecurity: Thirty years of evidence from the American General Social Survey. Industrial \& Labor Relations Review, 65, 263-285.

Bryson, A., Cappellari, L., \& Lucifora, C. (2004). Does union membership really reduce job satisfaction? British Journal of Industrial Relations, 42, 439-459.

Bryson, A., Cappellari, L., \& Lucifora, C. (2010). Why So Unhappy? The Effects of Unionization on Job Satisfaction. Oxford Bulletin of Economics and Statistics, 72, 357-380.

Bulger, C. A. (2001). Union resources and union tolerance as moderators of relationships with sexual harassment. Sex Roles, 45, 723-741. doi:10.1023/A:1015684202115

Church, A. H., \& Waclawski, J. (2007). Designing and using organizational surveys: A seven-step process. John Wiley \& Sons.

Cowart, L., Crowell, B., \& Kaye, B. (2013, July). Engagement leads to growth at Morrison. Retrieved from: http://www.talentmgt.com/articles/engagement-leadsto-growth-at-morrison

Dernovsek, D. (2008). Engaged employees. Credit Union Magazine, 74, 42-46.

Edmondson, V. C., Barnes, J., \& Gupte, G. (2008). Weakness in numbers: Towards an understanding of employees of color's responses to organizational research efforts. Journal of Behavioral and Applied Management, 10, 89-109.

Gallup. (2002, April). The high cost of disengaged employees. Business Journal. Retrieved from: http:/www.gallup.com/businessjournal/247/the-high-cost-ofdisengaged-employees.aspx 
Gallup. (2012). Engagement at work: Its effect on performance continues in tough economic times. Retrieved from:

http://www.gallup.com/services/176657/engagement-work-effect-performancecontinues-tough-economic-

$\%$ 20times.aspx?utm_source=engagement $\% 20$ work $\% 20$ effect $\% 20$ performance $\& u$ tm_medium $=$ search $\&$ utm_campaign $=$ tiles

Gobo, G. (2004). Sampling, representativeness and generalizability. Qualitative Research Practice, 435 - 456. Retrieved from:

http://ggobors.ariel.ctu.unimi.it/repository/ggobors/sage2004.pdf

Gordon, M. E., \& Denisi, A. S. (1995). A re-examination of the relationship between union membership and job satisfaction. Industrial \& Labor Relations Review, 48, 222-236.

Hammer, T. H., \& Avgar, A. (2005). The impact of unions on job satisfaction, organizational commitment, and turnover. Journal of Labor Research, 26, 241266.

Harter, J. K., Schmidt, F. L., Killham, E. A., Asplund, J. W. (2012). Q12 meta-analysis. Gallup. Retrieved from: http://strengths.gallup.com/private/Resources/Q12MetaAnalysis_Flyer_GEN_08\%2008_BP.pdf

Heberlein, T. A., \& Baumgartner, R. (1978). Factors affecting response rates to mailed questionnaires: A quantitative analysis of the published literature. American Sociological Review, 43, 447-462. doi:10.2307/2094771

Heywood, J. S., Siebert, W. S., \& Wei, X. (2002). Worker sorting and job satisfaction: The case of union and government jobs. Industrial \& Labor Relations Review, 55, 595-609.

Hinkin, T., \& Holtom, B. (2009). Response rates and sample representativeness: Identifying contextual response drivers. In D. Buchanan \& A. Bryman (Ed.), Handbook of Organizational Research Methods (pp. 451-464). Los Angeles, CA: Sage Publications.

Hogler, R., Hunt, H., \& Weiler, S. (2015). Killing unions with culture: Institutions, inequality, and the effects of labor's decline in the United States. Employee Responsibilities \& Rights Journal, 27, 63-79. doi:10.1007/s10672-014-9257-y

Irvine, D. (2009). Employee engagement: What it is and why you need it. Business Week Online, 12. 
Kahn, W. A. (1990). Psychological conditions of personal engagement and disengagement at work. Academy of Management Journal, 33, 692-724. doi: $10.2307 / 256287$

Manfreda, K. L., Berzelak, J., Vehovar, V., Bosnjak, M., \& Haas, I. (2008). Web surveys versus other survey modes: A meta-analysis comparing response rates. International Journal of Market Research, 50, 79-104.

Maslach, C., Schaufeli, W. B., \& Leiter, M. P. (2001). Job burnout. Annual Review of Psychology, 52, 397-422.

Mellor, S., \& Golay, L. M. (2014). Gender harassment and negative mental health: What labor unions can do to help union women. Employee Responsibilities and Rights Journal, 26, 21-34. doi:10.1007/s10672-012-9203-9

Mertler, C. A. (2003). Patterns of response and nonresponse from teachers to traditional and web surveys. Practical Assessment, Research \& Evaluation, 8(22). Retrieved from http://www.pareonline.net/ getvn.asp?v=8\&n=22.

Modern Survey. (2013). State of engagement: Unveiling the latest employee engagement research. Retrieved from: http://www.modernsurvey.com/wpcontent/uploads/2013/12/The-State-of-Engagement-Report-Fall-2013.pdf

Odewahn, C. A., \& Petty, M. M. (1980). A comparison of levels of job satisfaction, role stress, and personal competence between union members and nonmembers. Academy of Management Journal, 23, 150-155.

Ott, B. (2007). Investors, take note: Engagement boosts earnings. Gallup Management Journal Online, 1.

Renaud, S. (2002). Rethinking the union membership/job satisfaction relationship: some empirical evidence in Canada. International Journal of Manpower, 23, 137-150.

Rich, B., LePine, J. A., \& Crawford, E. R. (2010). Job engagement: Antecedents and effects on job performance. Academy of Management Journal, 53, 617-635. doi:10.5465/AMJ.2010.51468988

Robison, J. (2006). A caterpillar dealer unearths employee engagement. Gallup Management Journal Online, 1.

Saari, L. M., \& Scherbaum, C. A. (2011). Identified employee surveys: Potential promise, perils, and professional practice guidelines. Industrial and Organizational Psychology: Perspectives on Science and Practice, 4, 435-448. doi:10.1111/j.1754-9434.2011.01369.x 
Schaufeli, W. B., Salanova, M., González-Romá, V., \& Bakker, A. B. (2002). The measurement of engagement and burnout: A two sample confirmatory factor analytic approach. Journal of Happiness Studies, 3, 71-92. doi:10.1023/A:1015630930326

Schwochau, S. (1987). Union effects on job attitudes. Industrial \& Labor Relations Review, 40, 209-224.

Skalland, B. (2011). An alternative to the response rate for measuring a survey's realization of the target population. Public Opinion Quarterly, 75, 89-98. doi:10.1093/poq/nfq072

Sugheir, J., Coco, M., \& Kaupins, G. (2011). Perceptions of organizational surveys within employee engagement efforts. International Journal of Business \& Public Administration, 8, 48-61.

Thompson, L. F., \& Surface, E. A. (2007). Employee surveys administered online attitudes toward the medium, nonresponse, and data representativeness. Organizational Research Methods, 10, 241-261.

Tomaskovic-Devey, D., Leiter, J., \& Thompson, S. (1994). Organizational Survey Nonresponse. Administrative Science Quarterly, 39, 439-457.

Western, B., \& Rosenfeld, J. (2011). Unions, norms, and the rise in US wage inequality. American Sociological Review, 76, 513-537.

Wiseman, F., \& Billington, M. (1984). Comment on a standard definition of response rates. Journal of Marketing Research, 21, 336-338. doi:10.2307/3151610

Wyse, S. (2012, August 24). 11 Types of Employee Surveys. [Web log comment]. Retrieved from: http://www.snapsurveys.com/blog/11-types-employee-surveys/ 


\section{Appendix}

\section{Survey Question Themes}

Vigor

1. Invigorate

2. Timeliness in completing tasks

3. Adapting to new methods of working

4. Adapting to new roles and responsibilities

5. Self-Development

\section{Dedication}

6. Contribution to company success

7. Belonging

8. Personal Achievement

9. Dedication *

10. Pride *

11. Volunteering *

Absorption

12. Ability to focus

13. Satisfaction with job *

14. Satisfaction with company *

* Indicates that survey questions were not included in 2011 administration year 